\title{
Innovations in Teaching and Learning during a Time of Crisis
}

\section{Claire Major ${ }^{1}$}

Published online: 4 June 2020

(C) Springer Nature B.V. 2020

During the COVID-19 pandemic higher education institutions have faced many challenges, and among these are questions about how best to offer instruction in the face of sudden and mandatory college closures as well as in light of uncertainties about when campuses might open again. Coupled with these challenges have been signs that higher education is more innovative and flexible than we might have imagined, particularly when it comes to teaching and learning. As college and university educators have navigated the shifting landscape, they have found new and innovative ways to use technology to accomplish instructional goals; and they will most likely have reason to continue in the path of innovation going forward.

With the advent of mass remote instruction, college and university faculty members have had to determine how to teach online quickly, with the knowledge that many students did not sign up for online learning and may only have mobile devices coupled with limited internet access. Educators have been remarkable in putting workable short-term technological solutions for remote teaching and learning in place. As a result, the adoption of technology for teaching and learning in recent months has been unprecedented, with synchronous learning taking the fore initially. In particular, video-conferencing apps like Zoom and Skype have provided faculty and students a lifeline during this challenging time.

With the close of the spring academic term, however, colleges and university teachers around the world have recognized that there has been a shift in the way that we offer instruction, at least for the foreseeable future, as students may or may not return to campus in the fall. While some institutions have announced that they will be virtual in the fall, others have announced that students will return to campus; but the question of whether that will happen or not looms large. Some institutions have not yet made decisions. At the very least, many faculty members now find themselves planning for fall in a way that allows them to be flexible about whether the teaching they do will occur onsite or online. What this means in practice is that we need to be prepared to teach fully onsite and to shift to fully online teaching at a moment's notice if an unanticipated campus closure should require it. As a result, many faculty members are now realizing that remote learning is just a first step in a longer journey to offering high quality online education. They are taking up new tools, which allow for

Claire Major cmajor@ua.edu 
synchronous or asynchronous learning. Offering high-quality online instruction by the fall term under these conditions is taking a huge amount of planning and work from those of us in the teaching trenches. Being ready for anything requires rethinking what we typically do in the college classroom, including reframing and reconceptualizing communication, engagement, community, and more. And faculty members are rising to the challenge as is evidenced by the number of discussions emerging on campuses, across social media, and through professional organizations. We are all discussing a number of ways to teach, including planning for fully online, blended, and hybrid instruction. Some of us are even considering HyFlex (hybridflexible) models in which students themselves have the choice within a single course of whether to learn asynchronously online only or through blended delivery with onsite or synchronous video conferencing for class meetings. Clearly institutions can and should provide support to faculty members as they plan for multiple methods of instruction through instructional design support, technological training, assistance with instructional delivery, and other related issues and challenges.

It stands to reason that the demand for online offerings will continue to grow even after colleges and universities reopen their campuses for onsite instruction. Even before the pandemic, many institutions were seeing declines in enrollment for campus-based programs and parallel increases in enrollment for their online courses. Parents and students themselves are likely to want options that allow them to continue their studies without a risk to personal health and safety. This shift will necessitate continued shifts in our thinking about what teaching and learning in higher education means and how we can best accomplish it. As a result, distance education and online learning likely will evolve quickly, and we will likely see very different models of instruction going forward. Institutions can help faculty members prepare for these changes and support them as they carry them out.

The faculty will continue to innovate as the situation demands. As Plato suggested, "necessity is the mother of invention." In this time of crisis, the necessity of offering instruction online is fostering the invention of new ways of teaching and learning in higher education. Institutions need to stand ready to offer the support that faculty will need in order to do this remarkable and innovative work leading our institutions into the future.

Publisher's Note Springer Nature remains neutral with regard to jurisdictional claims in published maps and institutional affiliations. 